Boston University School of Law

Scholarly Commons at Boston University School of Law

Faculty Scholarship

$1-2018$

\title{
Can Rationing Through Inconvenience Be Ethical?
}

Nir Eyal

Paul Romain

Christopher Robertson

Boston University School of Law

Follow this and additional works at: https://scholarship.law.bu.edu/faculty_scholarship

Part of the Health Law and Policy Commons

\section{Recommended Citation}

Nir Eyal, Paul Romain \& Christopher Robertson, Can Rationing Through Inconvenience Be Ethical?, 48 Hastings Center Report 10 (2018).

Available at: https://scholarship.law.bu.edu/faculty_scholarship/964

This Article is brought to you for free and open access by Scholarly Commons at Boston University School of Law. It has been accepted for inclusion in Faculty Scholarship by an authorized administrator of Scholarly Commons at Boston University School of Law. For more information, please contact lawlessa@bu.edu. 


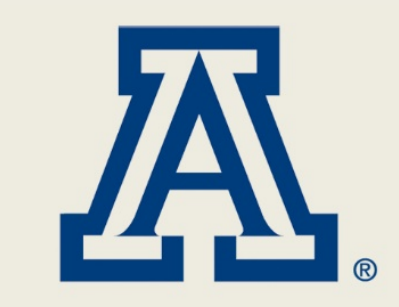

THE UNIVERSITY

OF ARIZONA。

James E. Rogers College of Law

\title{
Arizona Legal Studies Discussion Paper No. 19-03
}

\section{Can Rationing through Inconvenience Be Ethical?}

\author{
Nir Eyal \\ Harvard T.H. Chan School of Public Health \\ Harvard Medical School \\ Paul L. Romain \\ Beth Israel Deaconess Medical Center \\ Christopher Robertson \\ The University of Arizona \\ James E. Rogers College of Law
}

March 2019 


\section{Can Rationing through INCONVENIENCE Be Ethical?}

BY NIR EYAL, PAUL L. ROMAIN, AND CHRISTOPHER ROBERTSON

Using burdensome arrangements_-application processes, forms, waiting periods, and the like_-as a strategy for limiting the use of health care resources has been roundly but uncritically condemned. Under some conditions, it may be legitimate. It may even be preferable to direct rationing.

I $\mathrm{n}$ an influential essay, Gerald Grumet characterized "rationing through inconvenience" as a potent but secretive strategy for "slowing and controlling the use of services and payment for services by impeding, inconveniencing, and confusing providers and consumers alike." Donald Light similarly decried "practices [that] include rejecting claims in whole or in part for procedural or technical reasons, making the claims process and its rules extremely complex, and [ultimately] inducing claimants to give up." For clinicians, the phrase "rationing through inconvenience" usually evokes wasted time, unnecessary red tape, byzantine bureaucratic systems, escalating administrative expenditures, and even "ambiguity, deception, or harassment." 3 For patients, inconveniences like paperwork and travel can stand as a barrier to using insurance or accessing

Nir Eyal, Paul L. Romain, and Christopher Robertson, "Can Rationing through Inconvenience Be Ethical?," Hastings Center Report 48, no. 1 (2018): 10-22. DOI: $10.1002 /$ hast.806 needed health care. Recent efforts, for example, by the American College of Physicians, have sought to mitigate or eliminate administrative tasks and their adverse effects. ${ }^{4}$

However, inconvenience of service use is also a commonplace rationing mechanism for encouraging socially preferred choices. Consider the following examples:

- Pascaline Dupas and colleagues found that, in western Kenya, combining free provision of a chlorine water treatment (a diarrhea prophylactic) with a voucher system that imposes the inconvenience of having to redeem a coupon at a local store screened out 88 percent of those who would otherwise accept the product without using it. ${ }^{5}$ Similarly, Xiaochen Ma and coauthors found that giving Chinese children a voucher redeemable for eyeglasses in a store "modestly improved targeting efficiency" compared to handing out eyeglasses. ${ }^{6}$ 
- Rationing through inconvenience can also influence the particular health service consumed. Making a preferred treatment the default, overridden only with effort, has been proposed as a way of curbing health expenditure. ${ }^{7}$ For example, a physician might be required to navigate to the bottom of a computerized list to find the option that would allow her to refuse generic substitution. ${ }^{8}$ To the extent that a small inconvenience is used to shape preferred consumption, such nudges (recently called "effort taxes") arguably constitute rationing through inconvenience.

- An inconvenience, and its absence, can also affect patients' choice of provider. Americans rely on expensive specialists much more than patients in other countries do, in part because waits are longer in other countries. ${ }^{10}$ About one in five urgent care center users said they chose their provider because the location was "more convenient, compared to other facilities like hospitals, doctors' offices and community health centers." 11 Locating primary care clinics in convenient sites might likewise lure patients with nonemergency conditions away from expensive and less convenient emergency departments. ${ }^{12}$ Ironically, however, a study of pharmacy-based retail clinics "found that 58 percent of retail clinic visits for low-acuity conditions represented new utilization and that retail clinic use was associated with a modest increase in spending, of $\$ 14$ per person per year." ${ }^{33}$ Accordingly, commentators wonder whether other convenient, lower-priced options such as "telehealth" or kiosks offering testing in stores "could also end up leading to overall increases in health spending, despite being touted as cost-savers." 14

- Every U.S. state has a vaccination mandate but also has procedures for exempting individuals on

medical, religious, or philosophical grounds. Several authors have proposed "making [nonmedical] exemptions for immunizations more difficult to obtain." ${ }^{15}$ Their idea is to make the legal procedure for obtaining exemptions more "arduous" by, for instance, requiring "a notarized parental statement, counseling, and health department approval," as some states do. They point out that arduous exemption procedures are inversely related to the rate of nonmedical exemptions. ${ }^{16}$ Parents who are deeply and genuinely opposed to vaccinations may select to undergo the inconvenience, while children of the remainder get vaccinated.

For clinicians, the phrase "rationing through inconvenience" usually evokes wasted time and unnecessary red tape. However, inconvenience of service use is also a commonplace rationing mechanism for encouraging socially preferred choices.

In this article, we provide a comprehensive analysis and a normative assessment of rationing through inconvenience as a form of rationing. We argue that under certain conditions, rationing through inconvenience may turn out to serve as a legitimate and even a preferable tool for rationing; we propose a research agenda to identify more precisely when that might be the case and when, alternatively, rationing through inconvenience remains ethically undesirable. After defining and illustrating rationing through inconvenience, we turn to its moral advantages and disadvantages over other rationing methods.

\section{Rationing through Inconvenience: A Working Definition}

Ry "rationing through inconveBnience" in the health sphere, we refer to a nonfinancial burden (the inconvenience) that is either intended to cause or has the effect of causing patients or clinicians to choose an option for health-related consumption that is preferred by the health system for its fairness, efficiency, or other distributive desiderata beyond assisting the immediate patient. This definition can be unbundled.

First, rationing through inconvenience is a form of rationing. We take it as a starting assumption that rationing, understood as scarceresource prioritization, is inevitable and, in a society that has goals beyond optimizing health care for individual patients_-such as improving societal health care, education, or overall welfare-prudent and fair. ${ }^{17}$ Whether in public or private insur- 
good purpose, ethical investigation is unnecessary: such inconveniences only add offense to injury and are obviously undesirable.

Second, other policy uses of inconvenience lie outside our ambit. For example, many "nudges" 18 use inconvenience to help individuals make choices that are good for them; for example, making it comparatively harder to purchase junk food can nudge consumers toward healthier foods. ${ }^{19}$ Without a goal or an effect of allocating scarce resources better, these other uses of inconvenience do not count as rationing through inconvenience.

Third, our definition presumes inconvenience, by which we mean a burden that is not directly financial. An example of a nonfinancial burden is losing time (such as by standing in line or filling out a long form). Another is putting in effort (by redeeming a coupon to obtain health products or seeing a doctor for a prescription for antibiotics rather than buying them over the counter). A third example is getting hospitalized as a condition of reimbursement for medical expenses. ${ }^{20}$ Others are traveling to distant locations (to see a within-network specialist) and performing unpleasant tasks (waking up very early to be first in line or calling automated interactive customer service lines). Still another is being assertive (to convince an administrator that one's medical need is urgent enough to require immediate callback from the physician). In the health care context, the burden can fall on the patient or her advocates, including the clinician or other staff members. In some cases, this burden will be associated with a financial cost-possibly direct cost (paying for gas for transportation), indirect cost (paying for childcare while the parent is standing in line), or an opportunity cost (lost wages). ${ }^{21}$ However, that financial cost is not what makes the burden constitute rationing through inconvenience.

Fourth, rationing through inconvenience is indirect in that it operates through patient or clinician choice: the reduction in consumption is mediated by the impact on whether patients and clinicians choose a treatment and which treatment choices they make. This choicebased characteristic is shared by the central form of indirect rationing: financial cost sharing, such as with copays, deductibles, and capitated physician reimbursement. ${ }^{22}$ In that respect, rationing through inconvenience is unlike overt, or direct, rationing mechanisms such as allocation criteria and formularies. ${ }^{23}$ Still, as illustrated below, direct rationing mechanisms may also function as rationing through inconvenience. So can waiting lists. For example, organ waiting lists constitute rationing through inconvenience inasmuch as they dissuade consumption by patients who choose not to wait and instead forgo transplantation, seek alternative treatments, or step up their efforts to stay healthy.

Fifth, as we define it, rationing through inconvenience mobilizes only relatively small to moderate inconveniences. It leaves individuals with a genuine choice to forgo a benefit. When the alternatives are severe pain, true humiliations, or significant health risks, the patient could plausibly be said to lack real choice, making the rationing direct per our definition. Suffering mild knee pain while on a waiting list for a wholly elective knee surgery, for which waiting is safe but prolongs discomfort, can be a form of rationing through inconvenience, whose ethics can be debated. Suffering tremendously on the surgery waiting list as a disincentive against seeking the surgery is too burdensome to count as rationing through inconvenience. Drawing the line between moderate and severe inconvenience can be difficult, but the core idea is that the inconvenience cannot be "unduly burdensome," to borrow a phrase from constitutional jurisprudence around abortion law. ${ }^{24}$

Finally, by our definition, rationing through inconvenience need not be intended by payors or planners. It need not even be noticed by them.
For example, a form may be complex and inconvenient to fill, not intentionally but simply because exclusion criteria are genuinely complex or because the form writer is incompetent.

\section{An Illustration}

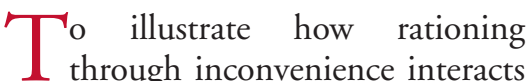
with, and sometimes dwarfs, direct rationing, we summarize data, previously reported in the literature, from a pharmacy benefits manager. ${ }^{25}$ The data covers preauthorization decisions concerning whether to allow patients access to an expensive drug for off-label usage, recorded over a one-year period. These data provide a one-year snapshot of actions taken in various cases. For simplicity of illustration, we treat the case flow as if it represented a complete set. Although our discussion is based on real data, we offer this as a conceptual illustration, not claiming generalizability to any other context. We assume that the manager's procedures were a bona fide attempt to allocate scarce health care resources more appropriately, not merely an attempt to avoid coverage obligations. The figure summarizes the data, with each symbol representing approximately 386 patients (and the physician treating each).

During this period, the manager received 38,621 requests to pay for use of expensive drugs off-label, which presumably were driven by physicians' recommending such care for their patients. Another unknown number of patients (on the left in the figure) who could have benefitted from the off-label use of a drug were deterred from even applying, presumably because the time and effort involved were predicted to be too burdensome for these patients or for their physicians. This is already a form of rationing through inconvenience. Further research should document these effects.

The data show that, upon receiving these 38,621 requests for off-label use of expensive drugs, the manager accepted 90 percent $(34,819$, group 
$\mathrm{I}$ in in the figure) and denied only 10 percent $(3,802$, group II in the figure).$^{26}$ Notably, even the vast majority of applicants who wound up successful suffered the inconvenience of making the application. For that reason and because appeal remained possible, this preauthorization process was not a pure example of direct rationing. It was arguably rationing through inconvenience.

There are more complete data at the next phase, concerning the 3,802 patients who were initially denied coverage of their drug (group II in the figure). Among them, 2,172 patients (6 percent of the original applicants, group II.A) simply went away, while 1,630 (4 percent of the original applicants, group II.B) submitted the necessary documents to appeal the initial denial decision. We cannot observe the counterfactual for the former 2,172 patients. How many would have been successful had they appealed? Nonetheless, these patients illustrate a second phase of rationing through inconvenience. In other words, most of the patients whose physicians initially believed that they could benefit from an off-label use of a drug but were denied chose to selfration, declining to further pursue this perceived medical need.

Of the 1,630 patients who went through additional hassle and submitted appeals, 1,404 (3.6 percent of the original applicants and 86 percent of appellants, group II.B.1) won their appeals. The 226 appellants who were ultimately rejected $(0.6$ percent of the original applicants and 14 percent of appellants, group II.B.2) are the only pure cases of direct rationing.

Overall, then, the pharmacy benefits manager's process directly rationed only 226 cases. That's a mere 0.6 percent of the applicants, all 38,621 of whom were inconvenienced by the application procedures, and some of whom were also inconvenienced by appealing. The process used rationing through inconvenience to deter 2,172 appeals and an unknown (but probably much larger) number of patients from applying in the first

place. When understanding the manager's procedure as a whole, we can conservatively say that, by deterring 2,172 cases of consumption, covert rationing through inconvenience was numerically ten times more significant than the overt direct rationing mechanism, which proscribed only 226 cases.

Current distributive ethics theory focuses primarily on the desired distributive pattern (namely, who should have how much and on what basis) and on the desired distributive currency (what should be distributed). ${ }^{27}$ We propose a research agenda on the morally right method of rationing. ${ }^{28}$ As we show, rationing through inconvenience has important advan-

\section{Decisions on allocation between candidate recipients do} not fall to the individual candidate to decide on her own. That said, we can count it as a limited advantage of rationing through inconvenience that it can preserve patient choice.

tages over direct rationing as well as over indirect rationing through a financial cost. It also has important disadvantages.

We now review several considerations that can affect the merits and demerits of rationing through inconvenience as compared to other rationing mechanisms, especially in health care. These considerations are clustered around

- increasing autonomy,

- reducing regressivity and influencing disparities,

- creating waste and conflicts of interest,

- increasing psychological impact on consumption decisions,

- reducing commodification and related considerations, and

- increasing public acceptability while reducing transparency. rationing through inconvenience is a form of indirect rationing, one could argue that it has the same important advantage of respect for autonomy.

However, rationing social resources, by definition, implicates the rights of other claimants on the resources, claimants such as other members of an insurance pool, who have an interest in keeping premiums low. As a result, no general strong obligation exists to "respect the autonomy of both patients and physicians." With rationing, decisions on allocation between candidate recipients do not fall to the individual candidate to decide on her own..$^{30}$ For example, a patient on a transplant list lacks any autonomy right to kick other patients off it, even if not getting the transplant would profoundly set back her autonomously chosen plan of life.

That said, we can count it as a limited advantage of rationing through inconvenience that it can preserve patient choice. Other things being equal, it is preferable to facilitate 


\section{How Rationing through Inconvenience Dwarfs One Pharmacy Benefits Manager's Direct Rationing}

For an unknown number, the predicted inconvenience of applying deters

application and consumption

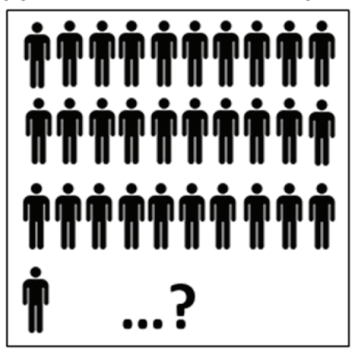

$\stackrel{\text { If }}{3} \begin{aligned} & 386 \text { patients and their physicians } \\ & \text { exposed to inconvenience }\end{aligned}$
官 = direct rationing
38,621 applications to access off-label drug

(inconvenience suffered)

$\begin{array}{ll}\text { I) } 90 \% \text { of applications accepted } & \text { II) } 10 \% \text { of applications denied }\end{array}$

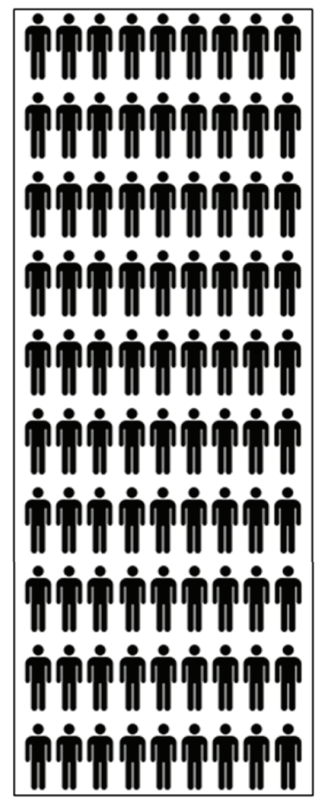

II.A) $6 \%$ of applications: after denial, no appeal filed

(predicted inconvenience of appeal deters consumption)

II.B) $4 \%$ of applications: after denial, appeal filed

1. $3.6 \%$ of applications accepted on appeal

2. $0.4 \%$ of applications denied (direct rationing)

The data we have plotted in this figure come from J. R. Teagarden et al., "Influence of Pharmacy Benefit Practices on Off-Label Dispensing of Drugs in the United States," Clinical Pharmacology and Therapeutics 91, no. 5 (2012): 943-45.

patient choice about, for example, whether to undergo inconvenience and receive the benefit-even regarding social-resource priorities over which patients lack strong autonomy rights.

One instrumental advantage of choice-based mechanisms is that they personalize the use of resources. Patients vary in their biology, circumstances, and values, with different medical and welfare needs. Personalization is the attempt to heed those different needs in the allocation of scarce resources. In contrast, without choice, health policy must proceed on "general presumptions," which, as John Stuart Mill wrote, "may be altogether wrong, and even if right, are as likely as not to be misapplied to individual cases." ${ }^{11}$ Society lacks pertinent information about individual variability in many areas where the "ordinary man or woman has means of knowledge immeasurably surpassing those that can be possessed by anyone else." ${ }^{32}$ By separating individuals who are willing to accept inconvenience to procure a good or service from ones who are not, rationing through inconvenience gathers that information and applies it to personalize rationing policy. For example, in Dupas and colleagues' experiment, families who know that they are unlikely to use the chlorine tablets are less likely to submit to the inconvenience of procuring them. ${ }^{33}$ In this way an inconvenience-an "ordeal" ${ }^{4}$ — may lead to more efficient allocation.

In direct rationing, collecting information from patients and personalizing care is more challenging. Consider the case of British cancer patient David Cook, who sought coverage for an expensive cancer drug from the British National Health System, although the National Institute for Health and Clinical Excellence (NICE) had at the time deemed that drug too expensive for the benefits it generates. NICE's cost-effectiveness recommendations depend on broad generalizations that are based on data about the average patient with the relevant disease. But for some patients, the likely benefits from the relevant drug are far greater than they are for the average patient. Cook persuaded a committee that, in his case, the relevant cancer drug would be cost effective, and this decision saved his life. ${ }^{35}$ Nevertheless, such direct rationing by committee is potentially expensive, slow, and haphazard in a world where millions of health care decisions are made every day. ${ }^{36}$ It also depends on information that is in the hands of the patients and their physicians and is subject to familiar self-reporting biases, with perverse incentives to offer misguiding information to gain access to the drug.

The sharing of otherwise private information can also be demeaning. 
Cook described pleading for his life in the face of a group of people who are free from his condition as humiliating. ${ }^{37}$ The committee's appropriate skepticism may exacerbate the humiliation ("Can you prove to us that you feel that much pain by night?"). The inevitable inquisitorial method recalls Jonathan Wolff's critique of conditional unemployment benefit program inspections that can shame and humiliate applicants. ${ }^{38}$

In contrast, rationing through inconvenience allows individual patients and clinicians to utilize their private information about the patient's case-including the patient's medical factors, physiological factors, personal circumstances, and personal values - to swiftly determine whether access to a treatment option is worth the burden of the inconvenience for her. In this way, rationing through inconvenience is similar to rationing through cost-sharing, where the theory is that patients who perceive the greatest benefits of a given treatment would rationally have the highest willingness to pay for that treatment and, in a free market, would bid up its price until they secured that treatment over others who value it less. This classic economic theory applies equally to rationing through inconvenience. Patients who perceive the greatest benefits from a treatment will similarly have what we could call the greatest "willingness to suffer" the inconveniences that may come with it. Assuming that central rationers can set the level of inconvenience for a given treatment to make it commensurate with its cost-benefit profile, rationing through inconvenience has the potential to achieve personalization as efficiently as cost sharing (and, as discussed below, without some of cost sharing's disadvantages).

The greater patient choice in rationing through inconvenience may matter from a certain luck-egalitarian viewpoint as well. According to luck egalitarianism, when a person's disadvantage results from her own avoidable choices, then her disadvantage is somewhat fairer than if she suffered the disadvantage without such choice. ${ }^{39}$ Luck egalitarians argue, for example, that justice does not require compensation for a financial loss consequent to a perfectly avoidable gamble; it requires compensation only for losses that are due to genetic incapacity, structural unemployment, and the like. In the rationing-through-inconvenience context, if certain people choose to avoid a reasonable inconvenience associated with some health care, then their resulting poorer outcomes may nonetheless be fair at the bar of luck egalitarianism.

Overall, then, rationing through inconvenience has certain autonomyrelated advantages over direct forms of rationing. Like cost sharing, it has

\section{Rationing through inconvenience is less regressive than}

rationing through cost sharing. All people have

twenty-four hours in a day, a limited attention span, and

\section{a body that can be in only one place at a time.}

the potential to shape consumption decisions in the directions preferred by a system rationer while preserving patient and physician choices. This gives it an advantage (albeit a defeasible one) in terms of personalization of decisions and a form of luck-egalitarian justice.

\section{Reducing Regressivity and Influencing Disparities}

Tn the current discussion, "regressivity" will designate the concern that a given mode of rationing tends to impose worse health care, health, or overall outcomes on poorer patients. Regressivity is, of course, a major concern about financial cost-sharing mechanisms of rationing. ${ }^{40}$ Other forms of rationing, such as centralized allocation and lotteries, avoid regressivity more easily.

The regressivity problem is smaller in rationing through inconvenience than in cost sharing. ${ }^{41}$ Some individuals have great wealth, while others are poor. But all people have twenty-four
Psychologically, this opportunity cost may make the rich loath to wait ${ }^{45}$ but the objective loss of utility need not be greater for the rich. A given dollar loss is also a smaller marginal loss of objective utility for those who have more dollars.

All that said, rationing through inconvenience can remain somewhat regressive. For example, in the United States, the majority of low-paid workers do not enjoy paid medical leave. Spending many hours in line for health care would impose onerous burdens on them. In some cases, wealthier individuals will be better able to navigate or minimize an inconvenience. For example, if a queue forms when the doors happen to open, wealthier individuals may be able to use private transportation to get there first. ${ }^{46}$ Wealthier individuals may also afford to live nearer to care centers, purchase a plan with a broader provider network, ${ }^{47}$ or even pay for concierge medicine. ${ }^{48}$ In the United States, wealthy patients spend less time on organ waiting 
lists partly because they pay doctors who list them earlier or, in rare cases, because they can indirectly buy their way into multiple organ waiting lists. ${ }^{49}$ Even in the more socialized Swedish public health care system, the lowest quartile of disposable income predicts longer waiting times for orthopedic (27 percent longer) and general surgery (34 percent), as compared to the highest quartile. ${ }^{50}$ Presumably, when lines become very long, the rich opt out of Sweden's public system and pay for surgeries out of pocket. Medical tourism enables rich Canadians to circumvent national queues and undergo treatment abroad. ${ }^{51}$ Finally, wealthier individuals can hire administrators to fill burdensome forms for them.

Rationing through inconvenience can certainly give rise to disparities that are not directly income based. Racial and ethnic disparities in wait times are well-documented in the United States. ${ }^{52}$ White, educated (and wealthy) patients have greater sway on triage officers; their doctors instruct them exactly what to do to meet residential or "seniority" criteria for transplant eligibility and how to score other scarce resources that are being directly rationed..$^{53}$ In a survey of Zambian HIV patients who were eligible for antiretrovirals, those who-dangerously-were not on antiretrovirals were 50 percent likelier than those on antiretrovirals to report that it would be very difficult for them to get to the clinic. ${ }^{54}$ In this instance, unintended inconvenience seemed to create a barrier to service utilization and therefore also a disparity. And the populations affected adversely were geographically, not economically, demarcated. Rationing through inconvenience can also be harder on patients with specific conditions. For patients living with depression, a long form or wait may require too much energy and emotional wherewithal.

Trying to erect barriers for some patients may end up dissuading others from claiming their rights. Mike Mitka has pointed out this kind of problem in a 2006 U.S. law that "intended to . . . reduce the number of illegal immigrants fraudulently receiving health care through Medicaid [by requiring] Medicaid recipients to provide more stringent documentation of citizenship, such as appearing at government offices with original documents like a birth certificate or driving license, rather than mailing photocopies of such items. " 55 But the mandate to document citizenship also imposed onerous paperwork burdens on those who were eligible to receive coverage and health care, driving tens of thousands of Americans off the program. ${ }^{56}$ This requirement was overridden in 2009, yet similar problems persist: as Patricia Illingworth and Wendy Parmet have noted, "[T]he complexity of the Medicaid application process, which can be daunting even for lowincome, English-speaking applicants . . deters many eligible immigrants from enrolling." 57

While it is clearly alarming when the impact of rationing through inconvenience is worse for disadvantaged populations (as, for example, when filling out paperwork is harder on patients with lower literacy), rationing through inconvenience is sometimes more challenging for advantaged populations. For a busy CEO, losing time by being forced to show up in person can be harder than for a much poorer, unemployed person without a binding schedule. The 2006 U.S. law that required citizenship documentation for joining Medicaid turned out to harm Latino patients less, and in two states to benefit them, since they had to keep their identity documentation intact anyway. ${ }^{58}$ When the impact is unequal between populations but the winners are socially disadvantaged, some would not consider the unequal impact unfair.

To reduce the bad disparities, rationing through inconvenience should be employed only carefully. Formal, periodic assessments should evaluate the impact on different populations. When a population is found to be adversely affected, rationing through inconvenience can be coupled with ameliorative measures. For example, forms can be given in multiple languages and geared to low levels of literacy. Social workers or specially trained experts can assist patients from adversely affected populations. When feasible, rationing through inconvenience policies should be calibrated to the realistic abilities of particular profiles of patients and providers, not as one-sizefits-all approaches. In some instances, a hardship waiver would be feasible and appropriate. A poor patient, or a provider in an overburdened community clinic, ${ }^{59}$ should not be held to the same standard of inconvenience as a more privileged person. Yet another approach to reducing the adverse impact on disadvantaged groups would be to maintain a plurality of optional inconveniences-stand in a long line or fill out a long form, for example. Finally, it may even be possible to compensate groups disproportionately and unfairly affected by inconvenience. If all these corrective measures turn out to be infeasible in a given context, though, and alternative rationing methods will avoid the disparate impact, then avoiding rationing through inconvenience may be better there.

\section{Creating Waste and Conflicts of Interest}

D ationing through inconvenience 1 is wasteful in a number of ways. At the most fundamental level, it deliberately wastes time and effort. As though that were not enough, like cost sharing, its impositions are typically most significant for the sick, who are relatively disadvantaged due to illness. For a health system designer to intentionally reduce the welfare of its intended beneficiaries and specifically to make care less accessible may seem perverse.

Worse still, from a system perspective, rationing through inconvenience is typically more wasteful than financial cost sharing. When patients 
pay money, it offsets the insurer's expenditures, enabling either lower insurance premiums and taxes or higher insurer profits and hence stronger businesses and, ideally, better services. At the very least, copays and deductibles enrich their recipient, thus transferring rather than destroying wealth. By contrast, most inconveniences have no "recipient." In that respect, they are pure waste. A disadvantage of all economic "ordeals" is the imposition of deadweight costs to qualify for a transfer." ${ }^{\prime \prime 0}$

But that doesn't show that rationing through inconvenience is inefficient overall. Ordeals can remain an efficient rationing tool on balance. ${ }^{61}$ If, for example, copays to dissuade excessive use of magnetic resonance imaging are deemed too regressive, then the commonly used rationingthrough-inconvenience strategy of forcing clinicians to fill out an extra form for MRI approval could save lots of money compared to no rationing, and lots of lives compared to crude direct rationing of MRI access.

Indeed, the deadweight cost may be trivial when a "micro-ordeal" 62 or a very small "effort tax" ${ }^{63}$ can dramatically change behavior. For instance, a reimbursable coupon rather than the product itself can target those likeliest to use the product. ${ }^{64}$ Similarly, making a generic drug the easy default often suffices to prompt patients to use it, saving large amounts over the branded product. An interesting question is what level of inconvenience optimizes overall efficiency. ${ }^{65}$

Besides, not every ordeal involves a complete deadweight cost. "Makework" is an inconvenience seeking partly to reduce applications for unemployment benefits and to strengthen the incentives of the unemployed to settle into workplaces. ${ }^{66}$ Yet makework can also produce social value, even if not optimally. Many bridges and dams have been built as makework projects.

On a conceptual level, note that a sheer credible threat of inconvenience may suffice to serve the purpose of soliciting private information about the

strength of a potential beneficiary's desire for a health product or service. Thus, what could be called "bluff ordeals" avoid the deadweight cost altogether. For instance, the emergency room nurse reminds patients who call in that, unlike their primary care clinic, the emergency room "usually" has a long wait. The nurse may read the same script even when patient load is low and the wait short (on which occasions her statement is misleading albeit true), so as to encourage a more cost-effective choice. Yet although such bluffs are theoretically possible, the lack of transparency will frequently make them unethical or unsustainable.

Rationing through inconvenience is wasteful in additional ways. Even when an inconvenience is enough

\section{As a rationing strategy, cost sharing works only if} individuals weigh costs against benefits, but in American health care, costs are often opaque to the patient at the time that she is making health care choices.

\section{Inconvenience is often more salient.}

to optimize the level of disincentive for the aggregate patient population, it may result in "false negatives," causing many patients not to get appropriate care. That's because, even among those patients who have equal need for the care, some have poor eyesight, mental or cognitive disabilities, chronic physical pain or less wherewithal and perseverance, making it harder to complete complicated forms, and others live farther from the clinic or have inflexible work hours, making it harder to queue up early in the morning.

That said, wasteful false negatives arise in cost sharing as well. Obviously, some people are short on money, and cost sharing has been shown to deter even worthwhile care. ${ }^{67}$ Even a small financial cost can limit the number of people who obtain a mosquito net in an impoverished malariaendemic area. ${ }^{68}$
These burdens can also create conflicts of interests. Physicians may prefer to minimize the inconvenience to themselves, their family, their office, and their other patients. But then, their primary interest in their immediate patient's good care conflicts with their secondary interests in, for instance, protecting office staff and family. These secondary interests may all be legitimate yet may also constitute conflicts of interest. ${ }^{71}$ And just like conflicts that stem from managed care or relationships with industry, they may undermine trust in physicians. When a physician recommends against a treatment option that would have highly inconvenienced the physician, the patient cannot know and might wonder whether the recommendation reflects medical considerations or the physician's aversion to inconvenience. 


\section{Increasing Psychological Impact on Consumption Decisions}

Oost sharing works as a rationing strategy only if individuals weigh the costs of a procedure against its benefits, but in the contemporary American web of health care systems, costs are often opaque to the patient at the time that she is making health care choices. ${ }^{72}$ When a patient checks into a hospital, she agrees to pay "all reasonable charges," and the hospitals and physicians rarely inform her about each procedure's cost to her. ${ }^{73}$ The bill that smites her with high copays arrives only months afterwards, too late for it to dissuade her from selecting cost-ineffective services.

Inconvenience is often more salient in advance. The very idea of inconvenience is that it is psychologically experienced, and filling out paperwork, traveling across town, or waiting in line often occur before one opts to receive treatment, rather than after. Information on other inconveniences could be made more perspicuous. Some U.S. hospitals' emergency rooms already advertise their wait times on billboards in order to attract patients to the hospital should they later need care. Similarly, patients could be notified of the wait time to see their own physician, and they could be allowed to switch to a trainee or nurse practitioner for an expedited visit.

This modest typical advantage that rationing through inconvenience has over cost sharing comes with three caveats. First, financial cost is sometimes salient even prior to the decision whether to accept care. Patients may be told about copays to see a doctor when they enroll in a plan or call for an appointment. Second, inconveniences and their magnitude are not always transparent in advance, either to patients or to clinicians. For example, a referring clinician might be unaware of the parking woes near the referral center. Third, any typical greater salience of inconvenience as compared to cost-sharing is a doubleedged sword because it can lead to underuse and because, as discussed below, it can also make rational priority setting less acceptable to the public.

\section{Commodification and Related Considerations}

$\mathrm{O}$ ne longstanding worry about using cost sharing for rationing is commodification: cost sharing seems to some to put a price on people's bodies or health or on professional integrity. In a market regime, patients, their families, and physicians must weigh the patient's health against money in the starkest way: Is grandpa's treatment really worth paying that amount of money? Is providing the care that, humanly and professionally, I feel I should give this patient worth my losing the dollars that exceed the capitation level? There may be said to be something denigrating $^{74}$ or corrupting ${ }^{75}$ about asking oneself such questions.

When the burden is inconvenience, things may seem different. Literal commodification objections are clearly moot. Health is weighed against time and comfort, not against dollars. Trade-offs remain, of course, but it is not clear whether they are as contentious - as allegedly denigrating or corrupting - as the literal commodification of bodies and health for money.

Rationing through inconvenience can, however, raise the inverse concern about respect for persons. Mobilizing our aversions to standing in line, to listening to annoying muzak on the phone, and jumping out of bed earlier exploit our bodily vulnerability to inconvenience-or our psychological and physical need for comfort. One might argue that inconveniences thereby turn us, or our bodies, against ourselves. Addressing more sinister situations, some contemporary thinkers have interpreted Kant's ideal of respect for persons as making such impositions morally problematic. ${ }^{76}$ Intentional bodily pressure in investigation or punishment is off limits in civilized societies.
Moreover, for patients who know that they do need that normally costineffective service or pill, rationing through inconvenience forces them to perform a very specific task, such as standing in a certain line or taking a bus to a remote point of service. ${ }^{77}$ A bedrock principle of U.S. contract law forbids courts from forcing "specific performance" of promised personal services. ${ }^{78}$ Instead, contract law cites respect for persons and utilitarian reasons for preferring that courts order money damages to compensate for breach of the contractual promise. On similar grounds, one might argue that imposing inconvenience-a specific task-is worse than imposing cost sharing.

Nonetheless, for rationing through inconvenience, it is not clear what moral weight, if any, to pay to these alleged problems. Even if respect for persons is in general important, people are torn all the time between wanting one thing for their bodies (food, rest) while having to do another (commute, work) in order to obtain goods they want. Indeed, even without rationing through inconvenience, the health care system often forces patients to perform highly specific tasks as a precondition of medical interventions to which they are fully entitled-for example, to open a pill bottle or to undergo a lengthy informed consent process. Concerns about lack of respect for persons may make sense when the inconvenience is severe, degrading, and contrived. As the impositions decrease, the moral objection arguably dissipates, keeping the minor forms of rationing through inconvenience that are the focus of the present article unobjectionably acceptable in that respect.

\section{Increasing Public Acceptability while Reducing Transparency}

7 ven if otherwise justified, the venience may be outrageous to the public. Therefore, it may never come to pass, and if it did, it may prove politically unstable. Doctors, in par- 
ticular, are already struggling to cut administrative chores and may fiercely object to compounding inconveniences to them. ${ }^{79}$

But options for rationing health care are never popular. No one loves cost sharing either, and no one loves being told flatly that something he is seeking will be denied him. In fact, in the United Kingdom, inconvenient queues are widely accepted as a fair method of resource allocation. And even in the United States, measles vaccination exemptions that are inconvenient to obtain and therefore reduce nonmedical exemption rates seem to encounter less hostile advocacy than does the explicit narrowing of exemption criteria. ${ }^{80}$

Besides, what the public protests depends on what the public knows, which depends on transparency. And rationing through inconvenience can sometimes occur by omission-that is, by avoiding interventions that would reduce inconvenience as opposed to actively introducing inconvenience-and in that form, it is often easy to protect from full scrutiny and protest. This may be what one health economist meant in explaining why informal inconveniencing is "one way to avoid the problem of having to choose. And governments don't choose very well. It's politically unpopular." ${ }^{81}$ For good and for ill, rationing through inconvenience may escape public scrutiny because it rarely requires formal legal intervention or high-level political approval. All it takes for a public hospital to use rationing through inconvenience is to intentionally fail to invest in added resources that would have alleviated long waits for a certain service. A public insurer can easily explain that processing times for insurance claims are long because administrators wish to ensure accuracy even if the full truth is that the insurer could expedite them by hiring more administrators or by abolishing the entire review process, given the rarity of refusals. By contrast, any increase in copays must be approved and made public, as protection against corruption.
How ethically important is maximal transparency about the intention to ration care and about the intention to ration it through inconvenience? Maximally transparent rationing schemes - ones with explicit, public criteria-can help prevent favoritism, discrimination, and some other forms of bad decision-making. They also facilitate accountability, democratic control over rationing decisions, and, allegedly, public trust in the system. ${ }^{82}$

Nonetheless, "rationing"- the " $R$ " word-remains hopelessly unpopular with most Americans, ${ }^{83}$ its fairness and inevitability notwithstanding. ${ }^{84}$ This unpopularity may be thought to justify some obliqueness in resource prioritization. In many areas of public life, forgoing maximal transparency may sometimes be the best compromise. ${ }^{85}$ Whether this is the case for rationing health care through inconvenience is a complex question, affected by philosophical considerations and context alike.

\section{A Research Agenda}

$\mathrm{O}$ ur analysis suggests that variants of rationing through inconvenience have both distinct advantages and distinct disadvantages over direct rationing and over cost-sharing forms of indirect rationing. The main advantages of rationing through inconvenience are that it maintains choice and mobilizes information privy to the patient and her physician better than direct rationing does and that, compared to cost sharing, rationing through inconvenience is less regressive and arguably less commodifying. However, rationing through inconvenience has distinct disadvantages, especially around disparities, waste, and conflicts of interest. Partial solutions may exist for some of these disadvantages. Ethical judgments about other matters, such as the public acceptability of rationing through inconvenience and its distinctive psychological impact on consumption decisions, depend on contingent political circumstances and on broader normative considerations.
More study should be given to rationing through inconvenience, particularly in order to understand when it works best, how its variants compare, and when it should not be used. Policy on inconvenience may seem harder to study and to systematize than policy on financial cost exposure, which has clear units, such as dollars; but in fact, the experience of paying a copay can vary dramatically from person to person, depending, for example, on the person's wealth and personal proclivity to loss aversion. And some inconveniences have units as well. We can discuss the minutes spent filling forms, for example. ${ }^{86}$ In short, both approaches merit and allow nuanced study and systematic policy analysis.

Questions for future scholarly exploration of rationing through inconvenience include the following:

- Where is rationing through inconvenience already in use, and when do threats of inconvenience actually prompt patients and clinicians to change consumption patterns in ways favorable to the health system? (Note, however, that readily available data may exclude patients who, foreseeing inconvenience, forgo filing paperwork.)

- How much disutility is actually created by each form of inconvenience-on average and for specific populations and in given situations-and can there be units of inconvenience, such as minutes spent on a form, and of the disvalue of the inconvenience for the person being inconvenienced?

- For any given intervention that aims to ration through inconvenience, what are its effects on individual and population health, on health-related quality of life, on health worker attrition to nonmedical professions, on bad disparities in health care, on public trust in physicians, and on other important indices? 
Once the impact of rationing through inconvenience is more fully understood and refined, policy-makers should compare it to alternative rationing mechanisms. In certain instances, rationing through inconvenience will turn out to be ethically worse and should be avoided. In others, it may turn out to be the best mechanism for the inevitable, rational, and fair task of rationing health care.

\section{Acknowledgments}

Earlier versions of this paper were presented at Roskilde University's Philosophy Department; the American Society for Bioethics and the Humanities 2016 annual conference; the University of Arizona's Clinical Bioethics Committee; Harvard Law School's Petrie Flom Center for Health Law, Policy, Biotechnology, and Bioethics; and Harvard's Edmond. J. Safra Center for Ethics. We thank the participants for detailed comments.

We also wish to thank Maryanne Chege, Michael Gill, Kasper LippertRasmussen, Holly Fernandez-Lynch, Margaret McConnell, Ole Norheim, Thomas Søbirk Petersen, Leah Price, Jesper Ryberg, Richard Zeckhauser, and audiences at the American Society for Bioethics and the Humanities 2016 annual conference; the Clinical Bioethics Committee at University Medical Center, Tucson, Arizona; Harvard Law School's Petrie-Flom Center; and the Edward J. Safra 30th Anniversary conference at Harvard University. Nir Eyal's work was partly funded by the Rector's award from Roskilde University, Denmark.

\section{Notes}

1. G. W. Grumet, "Health Care Rationing through Inconvenience: The Third Party's Secret Weapon," New England Journal of Medicine 321, no. 9 (1989): 607-11.

2. D. W. Light, "Life, Death, and the Insurance Companies," New England Journal of Medicine 330, no. 7 (1994): 498-500.

3. Grumet, "Health Care Rationing through Inconvenience"; J. L. Raper et al., "Uncompensated Medical Provider Costs Associated with Prior Authorization for Prescription Medications in an HIV Clinic," Clinical Infectious Diseases 51, no. 6 (2010):
718-24; C. P. Morley et al., "The Impact of Prior Authorization Requirements on Primary Care Physicians' Offices: Report of Two Parallel Network Studies," Journal of the American Board of Family Medicine 26, no. 1 (2013): 93-95; L. P. Casalino et al., "What Does It Cost Physician Practices to Interact with Health Insurance Plans?," Health Affairs 28, no. 4 (2009): w533-43.

4. S. M. Erickson et al., "Putting Patients First by Reducing Administrative Tasks in Health Care: A Position Paper of the American College of Physicians," Annals of Internal Medicine 166, no. 9 (2017): 65961; American Medical Association, "H160.919 Principles of the Patient-Centered Medical Home," June 9, 2014, accessed January 16, 2018, https://archive.li/7dtJo.

5. P. Dupas et al., "Targeting Health Subsidies through a Nonprice Mechanism: A Randomized Controlled Trial in Kenya," Science Magazine 353, no. 6302 (2016): 889-95.

6. X. Ma et al., "Ordeal Mechanisms and Training in the Provision of Subsidized Products in Developing Countries," unpublished manuscript, 2014, Mimeo, Stanford University; but see X. Ma et al., "Effect of Providing Free Glasses on Children's Educational Outcomes in China: Cluster Randomized Controlled Trial," BMJ 349 (2014): g5740.

7. E. L. Bogdan-Lovis and Margaret Holmes-Rovner, "Prudent Evidence-Fettered Shared Decision Making," Journal of Evaluation in Clinical Practice 16, no. 2 (2010): 376-81.

8. D. King et al., "Approaches Based on Behavioral Economics Could Help Nudge Patients and Providers toward Lower Health Spending Growth," Health Affairs 32, no. 4 (2013): 661-68; M. S. Patel, K. G. Volpp, D. A. Asch, "Nudge Units to Improve the Delivery of Health Care," New England Journal of Medicine 378, no. 3 (2018): 214-16.

9. C. R. Sunstein, The Ethics of Influence: Government in the Age of Behavioral Science (New York: Cambridge University Press, 2016).

10. K. Davis et al., "Mirror, Mirror on the Wall: How the Performance of the U.S. Health Care System Compares Internationally," The Commonwealth Fund, 2014, at http://www.commonwealthfund.org; A. M. Garber and J. Skinner, "Is American Health Care Uniquely Inefficient?," Journal of Economic Perspectives 22, no. 4 (2008): 27-50.

11. National Public Radio, Robert Wood Johnson Foundation, and Harvard T. H. Chan School of Public Health, "Patients' Perspectives on Health Care in the United States: A Look at Seven States \& the Nation," National Public Radio, February 26, 2016, at https://www.npr.org/assets/ img/2016/02/26/PatientPerspectives.pdf.
12. D. Boushy and I. Dubinsky, "Primary Care Physician and Patient Factors That Result in Patients Seeking Emergency Care in a Hospital Setting: The Patient's Perspective," Journal of Emergency Medicine 17, no. 3 (1999): 405-12; J. E. Coster et al., "Why Do People Choose Emergency and Urgent Care Services? A Rapid Review Utilizing a Systematic Literature Search and Narrative Synthesis," Academic Emergency Medicine 24, no. 9 (2017): 1137-49; A. Mehrotra et al., "Retail Clinics, Primary Care Physicians, and Emergency Departments: A Comparison of Patients' Visits," Health Affairs 27, no. 5 (2008): 1272-82; R. Penson et al., "Why Do Patients with Minor or Moderate Conditions That Could Be Managed in Other Settings Attend the Emergency Department?," Emergency Medicine Journal 29, no. 6 (2012): 487-91.

13. J. Scott Ashwood et al., "Retail Clinic Visits for Low-Acuity Conditions Increase Utilization and Spending," Health Affairs 35, no. 3 (2016): 449-55.

14. D. Mangan, "Clinics May Not Lower Health Insurance Costs," CNBC, March 7, 2016.

15. C. Constable, N. R. Blank, and A. L. Caplan, "Rising Rates of Vaccine Exemptions: Problems with Current Policy and More Promising Remedies," Vaccine 32, no. 16 (2014): 1793-97; S. B. Omer, "How to Handle the Vaccine Skeptics," New York Times, February 6, 2015; L. O. Gostin, "Law, Ethics, and Public Health in the Vaccination Debates: Politics of the Measles Outbreak," Journal of the American Medical Association 313, no. 11 (2015): 1099-1100.

16. Ibid.

17. M. Hall, Making Medical Spending Decisions (New York: Oxford University Press, 1997); D. W. Brock, "Health Care Resource Prioritization and Rationing: Why Is It So Difficult?," Social Research 74, no. 1 (2007): 125-48; R. D. Truog, "Screening Mammography and the 'R' Word," New England Journal of Medicine 361, no. 26 (2009): 2501-03.

18. C. R. Sunstein and R. H. Thaler, Nudge: Improving Decisions about Health, Wealth, and Happiness, 1st ed. (New Haven, CT: Yale University Press, 2008).

19. T. A. Smith, B.-H. Lin, and J.-Y. Lee, "Taxing Caloric Sweetened Beverages: Potential Effects on Beverage Consumption, Calorie Intake, and Obesity," in USDA Economic Research Report, July 2010, https://www.ers.usda.gov/webdocs/publications/44732/8310_err100_reportsummary_1_.pdf?v=41056; T. Andreyeva, M. W. Long, and K. D. Brownell, "The Impact of Food Prices on Consumption: A Systematic Review of Research on the Price Elasticity of Demand for Food," American Journal of Public Health 100, no. 2 (2010): 216-22.

20. A. L. Nichols and R. J. Zeckhauser, "Targeting Transfers through Restrictions 
on Recipients," American Economic Review 72 , no. 2 (1982): 372-77.

21. G. Tinghög et al., "Horizontal Inequality in Rationing by Waiting Lists," International Journal of Health Services 44, no. 1 (2014): 169-84; Kristin N. Ray et al., "Opportunity Costs of Ambulatory Medical Care in the United States," American Journal of Managed Care 21, no. 8 (2015): 567-74.

22. S. L. Burton et al., "The Ethics of Pharmaceutical Benefit Management," Health Affairs 20, no. 5 (2001): 150-63.

23. Ibid.

24. L. Greenhouse and R. Siegel, "Casey and the Clinic Closings: When 'Protecting Health' Obstructs Choice," Yale Law Journal 125, no. 5 (2015): 1428-80.

25. J. R. Teagarden et al., "Influence of Pharmacy Benefit Practices on Off-Label Dispensing of Drugs in the United States," Clinical Pharmacology and Therapeutics 91, no. 5 (2012): 943-45.

26. Ibid.

27. G. A. Cohen, "On the Currency of Egalitarian Justice,” Ethics 99, no. 4 (1989): 906-44.

28. See Hall, Making Medical Spending Decisions.

29. Burton et al., "The Ethics of Pharmaceutical Benefit Management," 152-53.

30. See Gostin, "Law, Ethics, and Public Health in the Vaccination Debates."

31. J. S. Mill, On Liberty, ed. Curry V. Shields (New York: Liberal Arts Press, 2017 [1869]), 93.

32. Ibid., 62.

33. Dupas et al., "Targeting Health Subsidies through a Nonprice Mechanism."

34. R. G. Frank and R. J. Zeckhauser, "Custom-Made versus Ready-to-Wear Treatments: Behavioral Propensities in Physicians' Choices," Journal of Health Economics 26 (2007): 1101-27.

35. P. Cox, "United Kingdom: Rationing Health by Cost," Rationing HealthWho Lives? Who Decides?, PRI's The World, Public Radio International, December 15, 2011, at https://www.pri.org/series/ rationing-health.

36. This is perhaps demonstrated by the United States' backlog of hundreds of thousands of Medicare appeals. See M. J. B. Lawrence, "Procedural Triage," Fordham Law Review 84 (2015): 79-130.

37. Cox, "United Kingdom: Rationing Health by Cost."

38. J. Wolff, "Fairness, Respect and the Egalitarian Ethos," Philosophy \& Public Affairs 27 (1998): 97-122.

39. Cohen, "On the Currency of Egalitarian Justice"; L. S. Temkin, "Egalitarianism Defended," Ethics 113, no. 4 (2003): 764-82.

40. C. T. Robertson, "Scaling CostSharing to Wages: How Employers Can Reduce Health Spending and Provide Greater
Economic Security," Yale Journal of Health Policy, Law, and Ethics 14, no. 2 (2014): 239-95.

41. Nichols and Zeckhauser, "Targeting Transfers through Restrictions on Recipients"; B. A. Olken, "Hassles versus Prices," Science 353, no. 6302 (2016): 864-65.

42. P. Dupas et al., "Micro-ordeals, Targeting, and Habit Formation," working paper, September 12, 2103, accessed January 16, 2018, https://economics.columbian. gwu.edu/files/downloads/Trade $\% 20-\% 20$ Micro-ordeals\%2009.16.13.pdf.

43. D. Baron, "Zambia: Rationing Health by Queue," Rationing HealthWho Lives? Who Decides?, PRI's The World, Public Radio International, December 16, 2010, at https://www.pri.org/series/ rationing-health.

44. D. Carpenter, "The Real Standing Problem in the Marriage Cases," The Volokh Conspiracy (blog), March 30, 2013, http:// www.volokh.com/2013/03/30/misbehavior-at-the-court/; V. Alatas et al., "Self-Targeting: Evidence from a Field Experiment in Indonesia," Journal of Political Economy 124, no. 2 (2016): 371-427.

45. I. O. Kuye, R. G. Frank, and J. M. McWilliams, "Cognition and Take-up of Subsidized Drug Benefits by Medicare Beneficiaries," JAMA Internal Medicine 173, no. 12 (2013): 1100-07.

46. Alatas et al., "Self-Targeting."

47. K. N. Ray et al., "Disparities in Time Spent Seeking Medical Care in the United States," JAMA Internal Medicine 175, no. 12 (2015): 1983-86; Agency for Healthcare Research and Quality, "Timeliness," in $\mathrm{Na}$ tional Healthcare Disparities Report (Rockville, MD: AHRQ, 2013), chapter 5.

48. M. Stillman, "Concierge Medicine: A 'Regular' Physician's Perspective," Annals of Internal Medicine 152, no. 6 (2010): 391-92.

49. B. S. Quon et al., "Disparities in Access to Lung Transplantation for Patients with Cystic Fibrosis by Socioeconomic Status," American Journal of Respiratory and Critical Care Medicine 186, no. 10 (2012): 1008-13; J. L. Hook and D. J. Lederer, "Socioeconomic Barriers to Lung Transplantation: Balancing Access and Equity," American Journal of Respiratory and Critical Care Medicine 186, no. 10 (2012): 937-39; P. Ubel, "Your New Liver Is Only a Learjet Away: Part 1 of 3," Forbes, June 24, 2015, http://www.forbes.com/sites/peterubel/2015/06/24/your-new-liver-is-only-alearjet-away-first-of-three-parts/.

50. Tinghög et al., "Horizontal Inequality in Rationing by Waiting Lists," 177.

51. M. Z. Bookman and K. R. Bookman, Medical Tourism in Developing Countries (London: Palgrave Macmillan, 2007); I. G. Cohen, "Protecting Patients with Passports: Medical Tourism and the Patient-Protective Argument," Iowa Law Review 95, no. 5
(2010): 1467-1567. Undergoing an operation abroad is also a hassle and potentially a form of rationing through inconvenience, however.

52. Ray et al., "Disparities in Time Spent Seeking Medical Care in the United States"; C. Y. Park, M. A. Lee, and A. J. Epstein, "Variation in Emergency Department Wait Times for Children by Race/Ethnicity and Payment Source," Health Services Research 44, no. 6 (2009): 2022-39; D. S. Carr, Y. Ibuka, and L. B. Russell, "How Much Time Do Americans Spend Seeking Health Care? Racial and Ethnic Differences in Patient Experiences," in The Impact of Demographics on Health and Health Care: Race, Ethnicity and Other Social Factors, ed. J. J. Kronenfeld (Bingley, U.K.: Emerald Group Publishing, 2010), 71-98.

53. Institute of Medicine, Unequal Treatment: Confronting Racial and Ethnic Disparities in Health Care (Washington, D.C.: National Academies Press, 2003); D. J. Lederer et al., "Racial and Ethnic Disparities in Survival in Lung Transplant Candidates with Idiopathic Pulmonary Fibrosis," American Journal of Transplantation 6, no. 2 (2006): 398-403; G. Thabut et al., "Geographic Disparities in Access to Lung Transplantation before and after Implementation of the Lung Allocation Score," American Journal of Transplantation 12, no. 11 (2012): 3085-93; Ray et al., "Disparities in Time Spent Seeking Medical Care in the United States."

54. M. P. Fox et al., "Barriers to Initiation of Antiretroviral Treatment in Rural and Urban Areas of Zambia: A Cross-Sectional Study of Cost, Stigma, and Perceptions about ART," Journal of the International AIDS Society 13 (2010): 10.1186/1758-2652-13-8.

55. M. Mitka, "Proving Citizenship Difficult," Journal of the American Medical Association 298, no. 10 (2007): 1153; D. C. Ross, "Medicaid Documentation Requirement Disproportionately Harms NonHispanics, New State Data Show: Rule Mostly Hurts U.S. Citizen Children, Not Undocumented Immigrants," Center on Budget and Policy Priorities, July 10, 2007, accessed January 16 2018, at https://www. cbpp.org/research/medicaid-documentation-requirement-disproportionatelyharms-non-hispanics-new-state-data.

56. Mitka, "Proving Citizenship Difficult."

57. P. Illingworth and W. Parmet, The Health of Newcomers: Immigration, Health Policy, and the Case for Global Solidarity (New York: NYU Press, 2017).

58. Ross, "Medicaid Documentation Requirement Disproportionately Harms NonHispanics, New State Data Show."

59. Ray et al., "Disparities in Time Spent Seeking Medical Care in the United States." 
60. Nichols and Zeckhauser, "Targeting Transfers through Restrictions on Recipients."

61. Ibid.; Olken, "Hassles versus Prices."

62. Dupas et al., "Micro-ordeals, Targeting, and Habit Formation."

63. Sunstein, The Ethics of Influence.

64. Dupas et al., "Targeting Health Subsidies through a Nonprice Mechanism."

65. Ma et al., "Ordeal Mechanisms and Information in the Provision of Subsidized Health Goods in Developing Countries"; Alatas et al., "Self-Targeting."

66. Nichols and Zeckhauser, "Targeting Transfers through Restrictions on Recipients"; Olken, "Hassles versus Prices."

67. Robertson, "Scaling Cost-Sharing to Wages."

68. P. Dupas, "What Matters (and What Does Not) in Households' Decision to Invest in Malaria Prevention?," American Economic Review 99, no. 2 (2009): 224-30.

69. Baron, "Zambia."

70. J. Pfeffer, "Why Health Insurance Companies Are Doomed," Fortune, October 20, 2014.

71. D. F. Thompson, "Understanding Financial Conflicts of Interest," New England
Journal of Medicine 329, no. 8 (1993): 573-76.

72. U. E. Reinhardt, "The Pricing of U.S. Hospital Services: Chaos behind a Veil of Secrecy," Health Affairs 25, no. 1 (2006): 57-69.

73. P. A. Ubel, P. Abernethy, and S. Yousuf Zafar, "Full Disclosure-Out-OfPocket Costs as Side Effects," New England Journal of Medicine 369, no. 16 (2013): 1484-86.

74. M. J. Radin, "Property and Personhood," Stanford Law Review 34, no. 957 (1983): 971-90.

75. M. Sandel, What Money Can't Buy: The Moral Limits of Markets (New York: Farrar, Straus and Giroux, 2012).

76. D. Sussman, "What's Wrong with Torture?," Philosophy \& Public Affairs 33, no. 1 (2005): 1-33.

77. Ma et al., "Ordeal Mechanisms and Information in the Provision of Subsidized Health Goods in Developing Countries."

78. R. E. Barnett, "Contract Remedies and Inalienable Rights," Social Philosophy and Policy 4, no. 1 (1986): 179-202.

79. Erickson et al., "Putting Patients First by Reducing Administrative Tasks in Health Care."
80. Omer, "How to Handle the Vaccine Skeptics"; Gostin, "Law, Ethics, and Public Health in the Vaccination Debates."

81. Baron, "Zambia."

82. N. Daniels and J. E. Sabin, Setting Limits Fairly: Learning to Share Resources for Health, 2nd ed. (Oxford, New York: Oxford University Press, 2008).

83. Truog, "Screening Mammography and the 'R' Word."

84. Brock, "Health Care Resource Prioritization and Rationing."

85. O. O'Neill, “Trust and Transparency," lecture 4 in Reith Lectures 2002, "A Question of Trust," BBC Radio 4, at http:// www.bbc.co.uk/radio4/reith2002/lectures. shtml; L. Lessig, "Against Transparency: The Perils of Openness in Government," The New Republic, October 9, 2009; C. T. Robertson and Aaron S. Kesselheim, eds., Blinding as a Solution to Bias: Strengthening Biomedical Science, Forensic Science, and Law (London: Academic Press, 2016).

86. J. S. Lubbers, "Paperwork Redux: The (Stronger) Paperwork Reduction Act of 1995," Administrative Law Review 49, no. 1 (1997): 111-21.

\title{
Another Voice $\quad$ Rationing Care through Collaboration and Shared Values
}

\author{
by JAMES E. SABIN
}

A lthough "rationing" continues to be a dirty word for the public in health policy discourse, Nir Eyal and colleagues handle the concept exactly right in their article in this issue of the Hastings Center Report. ${ }^{1}$ They correctly characterize rationing as an ethical requirement, not a moral abomination. They identify the key health policy question as how rationing can best be done, not whether it should be done at all. They make a cogent defense of what they call "rationing through inconve-

James E. Sabin, "Rationing Care through Collaboration and Shared Values," Hastings Center Report 48, no. 1 (2018): 22-24. DOI: 10.1002/ hast. 807 nience" as a justifiable allocational technique. And they wisely call for research on the effectiveness and fairness of this approach and other methods of rationing.

I fully agree with their approach to rationing and with their argument that the process they provocatively label "rationing through inconvenience" should not be rejected out of hand. But I believe they have underestimated two ways in which the practical impacts of rationing through inconvenience limit its potential usefulness: the asymmetry of its effect on patients and physicians and the way in which it reduces the capacity of health systems to learn from experience. 